\title{
Profit Maximization of GENCO's Using an Elephant Herding Optimization Algorithm
}

\author{
Sundar RAVICHANDRAN ${ }^{1 *}$, Manoharan SUBRAMANIAN ${ }^{2}$ \\ ${ }^{1}$ Department of Electrical \& Electronics Engineering, \\ Karpagam College of Engineering, Coimbatore, 641032, India* \\ sundareee1988@gmail.com (*Corresponding author) \\ ${ }^{2}$ Department of Electrical \& Electronics Engineering, \\ Karpagam College of Engineering, Coimbatore, 641032, India
}

\begin{abstract}
When electrical power systems are restructured managers look for satisfying several objectives that include: the working cost minimization and the profit for the unit commitment problems maximization. Power generating companies that comply with the two above mentioned objectives are able to provide good quality and reliable power at a cheaper cost. The individual power producers, schedule their generating units in such a way that they gain maximum profit. This is known as Profit Based Unit Commitment (PBUC). The target of this proposed work is to obtain an optimum generating schedule of the Power Generating Companies (GENCO's) and maximize the profit of power generating companies when the system is under various constraints like forecasted demand, minimum start-up /shutdown time, spot price, forecasted reserve and ramp rate limits. In order to address this problem, a new meta-heuristic approach called Elephant Herding Optimization (EHO) algorithm is presented. The method may help to solve the complex PBUC problems in the deregulated open market. The effectiveness of projected EHO is tested on various systems with various market conditions. The comparison of the test results with other optimization methods are presented and discussed taking into account their convergence characteristics, solution superiority and reliability.
\end{abstract}

Keywords: Deregulation, Elephant herding optimization, Profit based unit commitment.

\section{Introduction}

Restructuring of electric power system network is taking place all over the world. During 90's, worldwide power network companies and many electric utilities started using deregulation instead of vertically integrated structures. The traditional and vertically regulated power industry is replaced by horizontally regulated system therein generation, transmission and distribution are unbundled. The deregulation of the power system created market-based competition in an open electricity pool. Due to the developments in the power industry, the entire network comprising the generation process, scheduling, and running methods are required to be customized in regulated power system network. But it is a very complex process since electricity policy and the applications differ from country to country. This market-based power industry is not yet implemented in Tamil Nadu, India, where the system is owned by the state and operated as vertically integrated.

The restructuring of the power system has unbundled the responsibilities into three categories. They are i. Generation companies (GENCO's), ii. Transmission companies (TRANSCO), iii. Distribution companies (DISCO). In order to balance the supply and demand of the system to preserve the system precautions and consistency, a focal facilitator named Independent System Operator (ISO) is used. In this vertically integrated system, the Customers can choose their individual power supplier which improves the efficiency of the power generation and distribution, delivers at a reduced price with high quality. In this deregulated structure competition is created between GENCO's. Most of the conventional optimization methods are to be modified to address the open market competition. Sequentially, the unit commitment approach with profit maximization plays an important role in the competitive pool power market.

In a deregulated power system, the unit commitment problem with multi-objective function is exposed to various system constraints. The determination of generator scheduling in a power system is a complex optimization problem. Earlier the electric utilities had an appeal to satisfy the customer demand and forecasted reserve. Be that as it may, in the competitive power market, the GENCO's are not mandatory to equalize the power demand. The prepared load schedule may generate less than the forecasted load requirement and reserve with more profit under various constraints. This problem is stated as Profit based 
unit commitment problem. To increase the profit of the GENCO, it is necessary to compute the amount of power required to be introduced in the pool market based on the forecasted power demand and spot pricing at a particular time ' $t$ '. This is a more flexible and more complex problem under a deregulated environment. Different solutions were obtained for the unit commitment problem in the vertically regulated power system. In the recent days, the researchers concentrate on the best possible unit commitment algorithms for PBUC problems which will be more suitable for large size power system with low storage space and less computational time.

Based on the reviews carried out, large number of numerical optimization approaches were implemented to give solutions for complicated profit-based unit commitment. Many classical approaches were developed and implemented effectively. Some of the frequently used approaches are deterministic approach and metaheuristic approach. The deterministic approaches include enumeration method, priority list, Benders decomposition, branch and bound, dynamic programming method, Lagrangian relaxation technique and mixed integer technique which give local optimum solutions. The meta-heuristic approach includes Genetic algorithm (GA), Ant colony algorithm (ACA), Fuzzy logic(FL), artificial neural network(ANN), Tabu search(TS), particle swarm optimization (PSO), Muller method, Simulated annealing (SA), Memory management algorithm(MMA), Artificial immune system(AIS). Hybrid meta-heuristic methods like gravitational search LR-ANN, Dynamic programming with particle swarm optimization(PSO-DP), Particle swarm optimization based Lagrangian relaxation (LR-PSO), Multi-agent system(MAS), Improved pre-prepared power demand(IPPD) optimization, Teaching -learning optimization(TLO), Binary fish swarm algorithm (BFSA) are also presented for PBUC problems under restructured market.

The major limitation of this numerical approach is that they are unable to handle large size power system network and it fails to give an accurate solution within a short duration of time (ie.) Computational time is also more under the open market environment. Researchers developed a mimicking mechanism of biological evolution for optimization problem known as evolutionary algorithm. Chen \&Wang (2002) presented a cooperative algorithm for solving the UC problems. Contreras.et.al (2006) proposed a technique which determined best feasible solution with least computational time for a UC problem.

Chendur Pandian et.al (2014) \& Daneshi et.al presented a price-based solution for PBUC problem using fuzzy logic application. Mixed integer programming approach also addresses the problem and it is very practical with the consideration of uncertainties in the parameters. Sasaki et.al (2002) Used a Hopfield neural network approach to explore the probability to the UC problem when more inequality constraints were considered. Yamin et.al (2007) presented a method for Genco's PBUC in a day ahead open power market. The forecasted demand and generated power are also taken into account in the formulation to simulate the reserve uncertainty. Annakkage et.al (1995) investigated the application of parallel simulated annealing for unit commitment problem to reduce the computational time. Tabu search optimization has been applied to a combinatorial optimization problem. Mantawy et.al (1998) presented a unit commitment solution using Tabu search and introduced a new perturbation scheme for conventional UC problems.

Jing-yu et.al (2004) explored an approach with PBUC multi-agents' system having command agent, mobile agent and generator agent. They are placed with a distributed generator and operate together to get the satisfying operation of PBUC solution. Mori \&Okawa (2009) developed a Tabu search evolutionary PSO technique to PBUC. Here Genetic algorithm is derived from the biological model of evolution and it operates on the Darwinian principle of natural selection. Richter \& Sheble (1997) formed a bidding strategy using GA which maximizes the profit of the generating companies in the competitive pool electricity market. Richter \& sheble (2000) proposed a PBU using GA for Competitive environment which considers the demand constraints and it schedules for more profit. GA to PBUC provided optimal UC and also optimal MW values for demand, reserve. 
Vargas \& Chen (2010) combined LR and GA to solve PBUC problems. Attaviriyanupap et.al (2003) illustrated a hybrid LR-EP approach which actuates Genco's -generating schedule with the quantity of generated power and spinning reserve to be sold by the bidding process to get the maximum profit. Valenzuela et.al (2001) examined a new method of solution for individual power producer to tackle UC problem in electric power markets. Dimitroulas et.al (2011) explored a solution for PBUC problems by a hybrid model of GA and narrow search algorithm. To obtain the maximum profit with the best possible solution in the power market, Muller Optimization method is explored by Chandram et.al (2009). To maintain the high search capability, a new nodal ant colony optimization is introduced by Columbus et.al (2011). Srikanth Reddy et.al (2016) \& (2019) proposed a new approach called Binary firework's algorithm and binary whale optimization algorithm for PBUC problem to obtain a maximum profit for GENCO's. The dimension of the problem, complex programming and computation time are notified as major limitations of these methods. In this connection, the upgrading of the existing methods is required in order to obtain the optimal solution for PBUC problems.

In this research article, a swarm based meta-heuristic approach, Elephant Herding Optimization algorithm is presented to maximize the profit of GENCO's. EHO algorithm is stimulated by the herding activity of elephants. The food and shelter searching method is the main idea in this algorithm. This EHO method is implemented to solve the above -mentioned optimal scheduling and profit maximization under the deregulated power market. The article sequence is as follows: formulation of the multi-objective function for Profit Based Unit Commitment problem is dealt with in section 2. Section 3 presents the idea of the proposed Elephant Herding Algorithm. Section 4 discusses the implementation of EHO algorithm for the PBUC problems under deregulated pool market. Section 5 deals the meticulous outcomes and discussion followed by conclusion with comparative results of the work in section 6.

\section{Problem formulation}

The objective function varies between a costminimized conventional market and profit maximized restructured power market. The objective of the restructured power marketplace in PBUC is not only to reduce the participation cost but also to maximize the generating companies (GENCO's) profit under customary constraints like forecasted demand, reserve capacity, ramp rate limits, spot price, and minimum up/downtime. Revenue received from energy sold in the power market minus the net participation cost gives the profit of the GENCO.

\subsection{Objective Functions}

The objective function for profit maximization is given by

$$
\operatorname{Max}(P F)=\max (T R-T C)
$$

Where TR is total revenue, TC is the total operating cost for the power demand as well as the reserve demand.

$$
\begin{aligned}
& T R=\sum_{i=1}^{N} \sum_{t=1}^{T}\left\{\left(P_{i t}^{*} S P_{t}\right) U_{i t}\right\} \\
& T C=\sum_{i=1}^{N} \sum_{t=1}^{T}\left\{\left(C_{i t}\left(P_{i t}\right)+S_{i t}\right) * U_{i t}\right\}
\end{aligned}
$$

The total input cost is the summation of the power generation cost and cost calculated with startup/ shut down constraint of all generating units over whole optimum scheduling time. The fuel cost of generating unit ' $i$ ' at hour' $t$ ' is calculated by using the quadratic cost function.

$C_{i t}\left(P_{i t}\right)=a_{i}+b_{i} P_{i t}+c_{i} P_{i t}^{2}$

Where $\mathrm{C}_{\mathrm{it}}\left(\mathrm{P}_{\mathrm{it}}\right)$ is the Power generation cost of unit ' $\mathrm{i}$ ' at hour ' $\mathrm{t}$ '. $\mathrm{P}_{\mathrm{it}}$ is the output power from the generating unit " $i$ " at hour $t ; a_{i}, b_{i}$ and $c_{i}$ are fuel cost function coefficients of unit "i". $\mathrm{SP}_{t}$ is the forecasted power price at hour' $t$ '.

Startup cost:

$S_{i t}=S_{o i}\left[1-D_{i} \exp \left(\frac{T_{o f f, i}}{T_{d o w n, i}}\right)\right]+E_{i}$

Where $\mathrm{S}_{\text {it }}$ is Startup Cost $\mathrm{S}_{\mathrm{oi}}$ is Cold startup cost, $D_{i} \& E_{i}$ are the startup cost coefficients.

The various constraints considered for PBUC problems are as follows: 


\subsection{System Constraints}

\subsubsection{Load constraints or Demand constraints}

The balancing load demand constraints of PBUC are given as

$$
\sum_{i=1}^{N} P_{i t}^{*} U_{i t} \leq P D_{i} ; 1 \leq t \leq T
$$

Where $\mathrm{U}_{\mathrm{it}}$ equals to 1 if power generating unit ' $\mathrm{i}$ ' at hour $\mathrm{t}$ is $\mathrm{ON}$ and $\mathrm{U}_{\mathrm{it}}$ equals to 0 if power generating unit ' $i$ ' at hour $t$ is OFF. These two variables are known as Decision Variables. $\mathrm{PD}_{\mathrm{t}}$ is a power demand at hour ' $t$ '. In a deregulated power system, it is not obligatory to generate the same power as demand.

\subsubsection{Forecasted reserve constraints}

The forecasted whole system reserve capacity and GENCO's reserve capacity together form the inequality constraint as follows,

$\sum_{i=1}^{N} P_{i t} * U_{i t} \leq S R_{t} ; 1 \leq t \leq T$

Where $\mathrm{SR}_{t}$ is a forecasted reserve of hour ' $t$ '. This is also a Decision variable.

\subsection{Thermal Unit Constraints}

\subsubsection{Generation limit/ Dispatching limit}

The generation boundaries linked with the committed generating units,

$$
P_{i t}^{\min } \leq P_{i t} \leq P_{i t}^{\max } ; i=1,2,3 \ldots . . N, t=1,2,3 \ldots . T
$$

Where $P_{i t}^{\min } \& P_{i t}^{\max }$ are the min and max bound on the output power of unit 'i'.

\subsubsection{Minimum up/ Minimum downtime}

$T_{i}^{o n} \geq T_{i}^{u p}$

$T_{i}^{\text {off }} \geq T_{i}^{\text {down }}$

Where $T_{i}^{o n} \& T_{i}^{o f f}$ are the continuous ON and OFF time period. $T_{i}^{U P} \& T_{i}^{\text {down }}$ are the Min Up and Down time of unit ' $i$ '.

\subsubsection{Ramp up/Down limits}

The ramp up/down limits are the permissible timely modification in power generating stations,

$P_{i t}^{\max }=\min \left\{P_{i}^{\max }, P_{i(t-1)}+\tau R U_{i}\right\}$

$P_{i t}^{\min }=\max \left\{P_{i}^{\min }, P_{i(t-1)}+\tau \cdot R D_{i}\right\}$

PBUC time input step function $\tau$ is assumed to be 60 mins. Where, $\mathrm{RU}_{\mathrm{i}} \& \mathrm{RD}_{\mathrm{i}}$ are the ramp up and down limits for unit ' $\mathrm{i}$ '.

\subsubsection{Crew constraints}

When more units are in 'ON' state at an equal time period, then crew constraints are restricted.

\section{Elephant Herding Optimization}

Wang et.al (2015) introduced a metaheuristic algorithm called Elephant Herding optimization for solving multi-objective optimization problems. It is a nature-inspired algorithm that imitates the crowding activities of elephants in groups. It has a mixed behavior of swarm intelligence and evolutionary algorithm. The elephant behavior modeling has both abuse (Group updating operator) and examination (separating operator). In nature, elephants live together as a clan. Even though they belong to various groups, they will live together under the captainship of the eldest and largest female elephant matron of the group. The male elephants leave their nuclear family unit when they reach adulthood as shown in Figure 1.

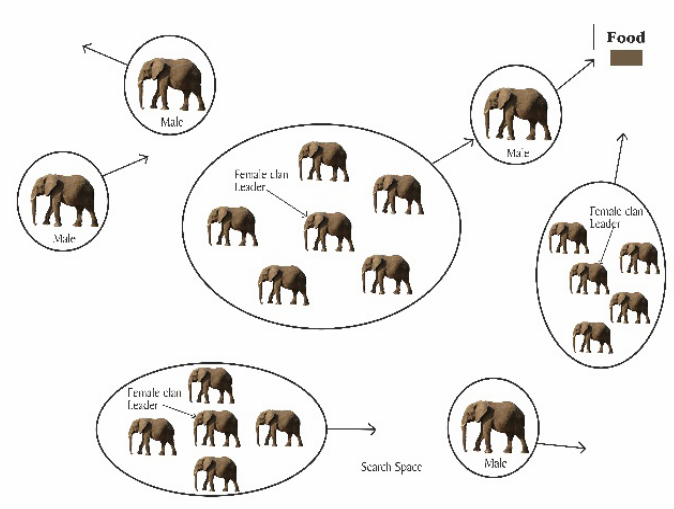

Figure 1. Elephant herding behavior nature 
In spite of the fact, though the male elephants live away, they make contact with their clan through low-frequency pulsations. From this, it is observed that exploration is done by male and exploitation is done by female respectively. When any of the male elephants finds the enhanced location, then the whole clan will move towards that position. The female elephant does a local search of that region. To form the global optimization method, the crowding activities of elephants are considered with (i) Clan updating operator-which updates the elephant's \& matron's current position in each clan, (ii) Separating Operator- which enhances the inhabitant range at every search period.

\subsection{Clan updating operator}

Initially, the total elephant population is assumed as ' $n$ ' clans. While organizing the elephants, clan updating operator is applied based on their fitness function. Each member $\mathrm{j}$ of the ith clan moves according to the elephant matriarch, $\mathrm{Ci}$ with best fitness value as,

$\gamma_{\text {new, } \mathcal{C}_{i, j}}=\gamma_{c}+\alpha *\left(\gamma_{\text {best } \mathcal{C}_{i}}-\gamma_{c_{i, j}}\right) * r$

Where $\gamma_{\text {new, Ci,j }}$ and $\gamma_{\mathrm{Ci}, \mathrm{j}}$ are recently restructured and old location of elephant $\mathrm{j}$ in group $\mathrm{C}_{\mathrm{i}}$, respectively. $\alpha €[0,1]$ is a level parameter which decides the impact of $i^{\text {th }}$ matron $\mathrm{C}_{\mathrm{i}}$ on $\gamma_{\mathrm{Ci}, \mathrm{j}}, \gamma$ best,Ci represents the matron $\mathrm{C}_{\mathrm{i}}$ which is the best individual elephant in group $\mathrm{C}_{\mathrm{i}}$ and $\mathrm{r} €[0,1]$ explained by R. Vijay, et.al (2018). The best elephant can't be updated in the group by eqn. 13

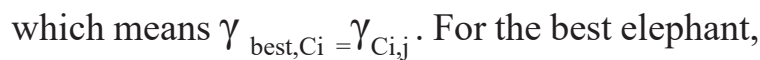
it can be updated accordingly,

$\gamma_{{ }_{\text {new },}, c_{i, j}}=\beta^{*} \gamma_{\text {center, }, c_{i}}$

$\beta €[0,1]$ is another tuning parameter which decides

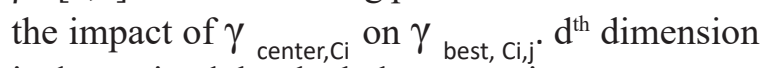
is determined by the below equation,

$$
\gamma_{\text {center, } c_{i, d}}=\frac{1}{n} * \sum_{j=1}^{n c i} \gamma_{c_{i, j, d}}
$$

Where the dimension limits are $1 \leq \mathrm{d} \leq \mathrm{D}$. Here $\mathrm{D}$ is the total dimension of the problem. $\mathrm{n}_{\mathrm{ci}}$ is the total quantity of elephants in the clan $\mathrm{Ci}$.

\subsection{Separating operator}

When the separating operator is applied in each interaction, the elephant is moving to a new position $\&$ replacing it with the worst fitness in the $\mathrm{i}^{\text {th }}$ group.

$\gamma_{{\text {worst }, c_{i}}_{i}}=\gamma_{\text {min }}+\left(\gamma_{\text {max }}-\gamma_{\text {min }}+1\right) * r$

Where $\gamma_{\max }$ and $\gamma_{\min }$ are max and min limit of the individual elephant's location, respectively. $\mathrm{r} €[01]$ is a kind of stochastic distribution. Therefore, the elephant herding algorithm implies the iterative applying 13-16 for a predefined no of iterations. The Population size and Maximum no. of iterations are indirectly controlled by the no. of clans and clan size, whereas $\alpha$ and $\beta$ are fixed for certain application.

\section{Implementation of EHOAlgorithm}

The PBUC optimization problem is accomplished using the $\mathrm{EHO}$ procedure following the steps mentioned below:

\section{Step 1:}

Read the GENCO's unit and system data like Generation limits, cost coefficients, min up/ downtime, etc.

Step 2:

Read the EHO parameters such as maximum no. of elephants, no. of clans, $\alpha$ and $\beta$.

Step 3:

Compute the feasible units for forecasted demand or Market price of all objectives Function.

Step 4:

Calculate the objective function (power generation, cost, revenue, etc.) for entire load scheduling time periods and Compute the PBUC schedule prevailing the system constraints. If it is completed, then go to the next step or else back to step 3.

Step 5:

Call the EHO algorithm and Set the iteration count $\mathrm{i}=1$ and assign the population size. Calculate the Fitness function (Profit of Units) for all of the solutions in each clan.

Step 6:

Update the clan operator with the best and worst position of the elephants using eqn. $13-16$ for the aforesaid objective function of PBUC problems. 


\section{Step 7:}

Separate the worst (local optimum) elephant using the separating operator by eqn. 16 . The elephant will communicate with others to update the current worst position among the iteration.

\section{Step 8:}

Check for the total no. of a clan. If it is reached then go to next step, otherwise go to step 5 with new values of $\alpha$ and $\beta$ which are normally assumed $€[0,1]$.

\section{Step 9:}

After updating the best and worst elephant (Global and local optimum), check for the optimum solution for the PBUC problem. If it is reached, then save the best simulation results and then stop the process otherwise change the PBUC variables and proceed to step 4 .

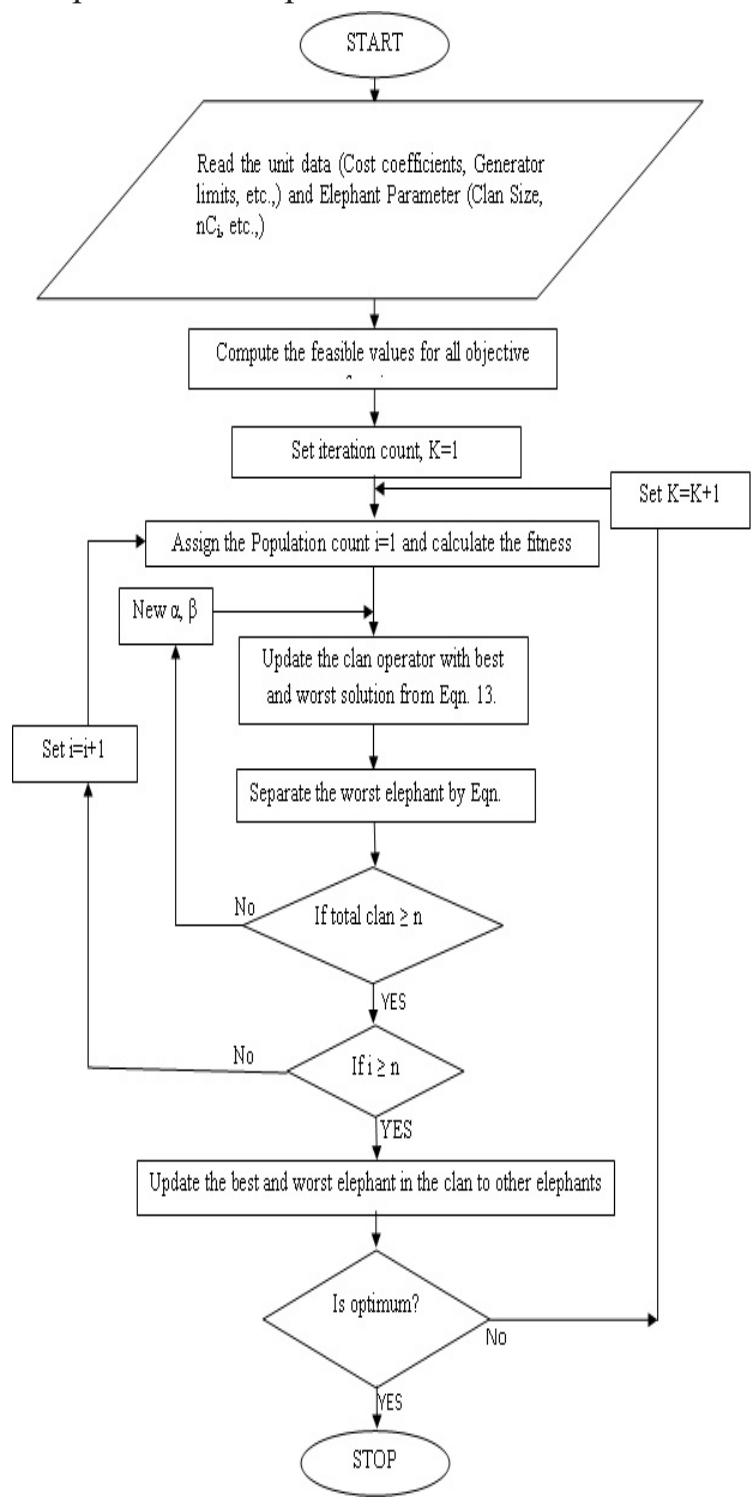

Figure 2. Flow Diagram of PBUC with proposed method

\section{Numerical Results and Discussion}

The elephant Herding Optimization algorithm was developed in MATLAB 7.10 and the machine configuration is Intel I5 processing unit with the $3.55 \mathrm{GHz}$ speed with $8 \mathrm{~GB}$ RAM. In this article, 2 GENCO's (Three units, and ten units) test systems were taken for simulation. The computational outcomes of Profit Based Unit Commitment acquired by the EHO algorithm for 2 GENCO's and the simulation outcomes were compared with the various standing optimization methods.

\subsection{GENCO I (3 Units 12-hour Schedule)}

Elephant Herding Optimization algorithm chooses only the best fit optimum allocation if the number of units is less than two. Before executing the PBUC-EHO algorithm, it is necessary to find an accurate hourly power demand of GENCO's and a scheduled period spot price. The generator cost function is always derived in the quadratic equation.

Table 1 is the system operating data for GENCO-I consisting of 3 units 10 bus system. When the generators are in Continuous operation, the abuse of min up/downtime limitations may be avoided.

Table 1. Unit cost and performance data of GENCO-I

\begin{tabular}{|l|l|l|l|}
\hline Parameter & G1 & G2 & G3 \\
\hline $\mathrm{P}_{\mathrm{mn}}(\mathrm{MW})$ & 600 & 400 & 200 \\
\hline $\mathrm{P}_{\mathrm{mx}}(\mathrm{MW})$ & 100 & 100 & 50 \\
\hline $\mathrm{a}($ Constant $)$ & 500 & 300 & 100 \\
\hline $\mathrm{b}$ (Linear) & 10 & 8 & 6 \\
\hline $\mathrm{C}$ (quadratic) & 0.002 & 0.0025 & 0.005 \\
\hline Initial Status & -3 & 3 & 3 \\
\hline Min up/downtime $(\mathrm{hr})$ & $3 / 3$ & $3 / 3$ & $3 / 3$ \\
\hline Startup cost $(\$)$ & 450 & 400 & 300 \\
\hline
\end{tabular}

Table 2 explains the simulation input parameter of Elephant Herding optimization algorithm. In view of the demand data and related spot pricing in the power market, the generating units are committing at regular time period. Table 3 clarifies the optimum allocation of GENCO-I at the end of 
each generation which defines the PBUC optimum schedule with revenue and profit. Figure 3 shows the performance of total cost, GENCO's revenue and its profit over 12 hours' time period. The profit is found to be enhanced from the graphical observation. Figure 4 and Figure 5 gives a comparative analysis from the optimum allocation of the PBUC schedule.

Table 2. Input Parameters of EHO

\begin{tabular}{|l|c|}
\hline Population size & 30 \\
\hline No. of Generations & 50 \\
\hline$\alpha$ & 0.5 \\
\hline$\beta$ & 0.1 \\
\hline Clan number & 5 \\
\hline Number of the elephants in each clan & 10 \\
\hline
\end{tabular}

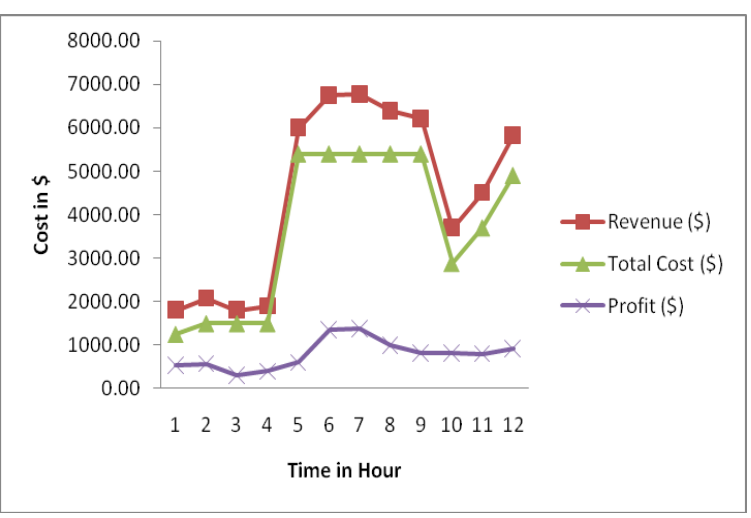

Figure 3. Performances of Total cost, Revenue, and Profit in GENCO-I

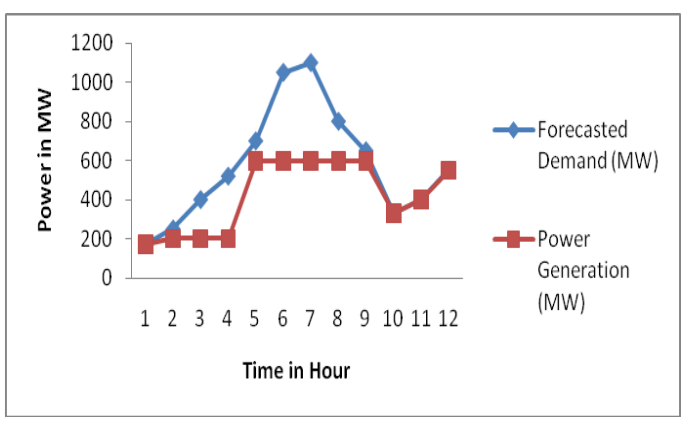

Figure 4. Comparison between power demand and power generation

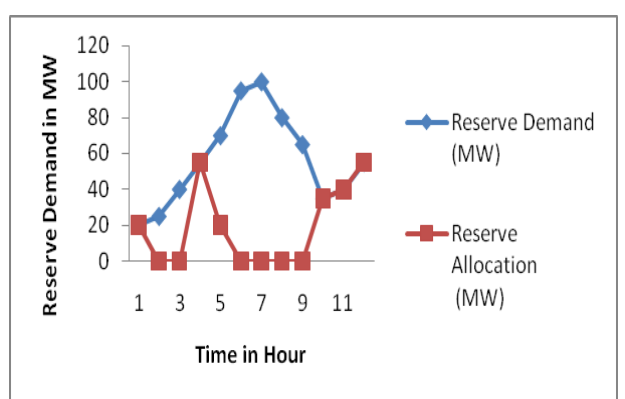

Figure 5. Comparison between Reserve power demand and reserve allocation

Table 4 provides a comparison between profits obtained with other optimization methods like LR-EP, MPPD-ABC, MMA.

Table 4. Profit comparison between proposed methods and existing methods for GENCO-I

\begin{tabular}{|l|l|l|}
\hline S. No & Scheme & Profit (\$) \\
\hline 1 & Swarup et.al & 9136 \\
\hline 2 & K Asokan et.al & 9457.50 \\
\hline 3 & A. Amudha et.al & 9168 \\
\hline 4 & EHO Method & 9735.5 \\
\hline
\end{tabular}

Table 3. Optimum Allocation of GENCO-I (3 units 10 Bus System)

\begin{tabular}{|l|l|l|l|l|l|l|l|l|l|}
\hline Hour & $\begin{array}{c}\text { Forecasted } \\
\text { Demand } \\
(\mathbf{M W})\end{array}$ & $\begin{array}{c}\text { Power } \\
\text { Generated } \\
\mathbf{( M W )}\end{array}$ & $\begin{array}{c}\text { Forecasted } \\
\text { spot Price } \\
\mathbf{( \$ / M W - h r )}\end{array}$ & $\begin{array}{c}\text { Reserve } \\
\text { Demand } \\
(\mathbf{M W})\end{array}$ & $\begin{array}{c}\text { Allocated } \\
\text { Reserve } \\
(\mathbf{M W})\end{array}$ & $\begin{array}{c}\text { Total Cost } \\
\mathbf{( \$ )}\end{array}$ & $\begin{array}{c}\text { Revenue } \\
\mathbf{( \$ )}\end{array}$ & $\begin{array}{c}\text { Profit } \\
\mathbf{( \$ )}\end{array}$ & $\begin{array}{c}\text { Profit } \\
(\mathbf{R s})\end{array}$ \\
\hline 1 & 170 & 170 & 10.55 & 20 & 20 & 1253.50 & 1793.50 & 540.00 & 37530.00 \\
\hline 2 & 250 & 200 & 10.35 & 25 & 0 & 1500.00 & 2070.00 & 570.00 & 39615.00 \\
\hline 3 & 400 & 200 & 9.00 & 40 & 0 & 1500.00 & 1800.00 & 300.00 & 20850.00 \\
\hline 4 & 520 & 200 & 9.45 & 55 & 55 & 1500.00 & 1890.00 & 390.00 & 27105.00 \\
\hline 5 & 700 & 600 & 10.00 & 70 & 20 & 5400.00 & 6000.00 & 600.00 & 41700.00 \\
\hline 6 & 1050 & 600 & 11.25 & 95 & 0 & 5400.00 & 6750.00 & 1350.00 & 93825.00 \\
\hline 7 & 1100 & 600 & 11.30 & 100 & 0 & 5400.00 & 6780.00 & 1380.00 & 95910.00 \\
\hline 8 & 800 & 600 & 10.65 & 80 & 0 & 5400.00 & 6390.00 & 990.00 & 68805.00 \\
\hline 9 & 650 & 600 & 10.35 & 65 & 0 & 5400.00 & 6210.00 & 810.00 & 56295.00 \\
\hline 10 & 330 & 330 & 11.20 & 35 & 35 & 2882.25 & 3964.00 & 1081.75 & 75181.63 \\
\hline 11 & 400 & 400 & 10.75 & 40 & 40 & 3700.00 & 4500.00 & 800.00 & 55600.00 \\
\hline 12 & 550 & 550 & 10.60 & 55 & 55 & 4906.25 & 5830.00 & 923.75 & 64200.63 \\
\hline & & & & & Total & $\mathbf{5 3 9 7 7 . 5 0}$ & $\mathbf{4 4 2 4 2 . 0 0}$ & $\mathbf{9 7 3 5 . 5}$ & $\mathbf{6 7 6 6 1 7 . 2 5}$ \\
\hline
\end{tabular}




\subsection{GENCO-II (10 units 24-hr schedule)}

Table 5 gives the system working information and the power demand data for 10 units' system. The ramp rate limits are calculated by using eqn.11 and 12 . With this ramp limit, the continuous load scheduling for PBUC problem can be obtained under the deregulated power market.
Table 6 gives the optimum load dispatch schedule of the GENCO-II with total operating costs, revenue, and profit over a period of 24 hours. GENCO-II receives high profit even though only a few units are operating at a particular period. Figure 6 and Figure 7 show comparisons of various test results provided in Table 6 . From Table 7, it can be observed that the total cost

Table 5. Unit cost and performance data of GENCO-II

\begin{tabular}{|l|c|c|c|c|c|c|c|c|c|c|}
\hline Parameter & G1 & G2 & G3 & G4 & G5 & G6 & G7 & G8 & G9 & G10 \\
\hline $\mathrm{P}_{\text {mn }}(\mathrm{MW})$ & 455 & 455 & 130 & 130 & 162 & 80 & 85 & 55 & 55 & 55 \\
\hline $\mathrm{P}_{\text {mx }}(\mathrm{MW})$ & 150 & 150 & 20 & 25 & 25 & 20 & 25 & 10 & 10 & 10 \\
\hline $\mathrm{a}$ (constant) & 0.00048 & 0.00031 & 0.00200 & 0.00211 & 0.00398 & 0.00712 & 0.00079 & 0.00413 & 0.00222 & 0.00173 \\
\hline $\mathrm{b}$ (linear) & 16.19 & 17.26 & 16.60 & 16.50 & 19.70 & 22.26 & 27.74 & 25.92 & 27.27 & 27.79 \\
\hline $\mathrm{c}$ (quadratic) & 1000 & 970 & 700 & 680 & 450 & 370 & 480 & 660 & 665 & 670 \\
\hline $\begin{array}{l}\text { Up / } \\
\text { downtime }\end{array}$ & $8 / 8$ & $8 / 8$ & $5 / 5$ & $/ 55$ & $6 / 6$ & $3 / 3$ & $3 / 3$ & $1 / 1$ & $1 / 1$ & $1 / 1$ \\
\hline $\begin{array}{l}\text { Rampup/ } \\
\text { down }\end{array}$ & $40 / 60$ & $62 / 73$ & $75 / 91$ & $51 / 109$ & $133 / 142$ & $119 / 257$ & $270 / 276$ & $51 / 83$ & $158 / 145$ & $152 / 90$ \\
\hline $\begin{array}{l}\text { Startup cost } \\
(\$)\end{array}$ & 4500 & 5000 & 550 & 560 & 900 & 170 & 260 & 30 & 30 & 30 \\
\hline Initial Status & 8 & 8 & -5 & -5 & -6 & -3 & -3 & -1 & -1 & -1 \\
\hline
\end{tabular}

Table 6. Operating costs, Revenue and Profit for GENCO-II

\begin{tabular}{|c|c|c|c|c|c|c|c|c|c|}
\hline $\begin{array}{l}\text { Time } \\
\text { (Hour) }\end{array}$ & $\begin{array}{c}\text { Power } \\
\text { Demand } \\
\text { (MW) }\end{array}$ & \begin{tabular}{|c}
$\begin{array}{c}\text { Generated } \\
\text { Power } \\
\text { (MW) }\end{array}$ \\
\end{tabular} & $\begin{array}{c}\text { Reserve } \\
\text { Demand } \\
\text { (MW) }\end{array}$ & $\begin{array}{c}\text { Allocated } \\
\text { Reserve } \\
\text { (MW) } \\
\end{array}$ & $\begin{array}{c}\text { Forecasted } \\
\text { Spot Price } \\
(\$ / M W)\end{array}$ & $\begin{array}{l}\text { Startup } \\
\text { Cost(\$) }\end{array}$ & $\begin{array}{c}\text { Total } \\
\text { operating } \\
\text { Cost }(\$)\end{array}$ & $\begin{array}{c}\text { Revenue } \\
\text { (\$) }\end{array}$ & $\begin{array}{c}\text { Profit } \\
\text { (\$) }\end{array}$ \\
\hline 1 & 700 & 700 & 70 & 70 & 22.15 & 0 & 15246 & 17056 & 1810 \\
\hline 2 & 750 & 750 & 75 & 75 & 22.00 & 0 & 15864 & 18150 & 2286 \\
\hline 3 & 850 & 850 & 85 & 60 & 23.10 & 0 & 17353 & 21021 & 3668 \\
\hline 4 & 950 & 910 & 95 & 0 & 22.65 & 0 & 17353 & 20364 & 3011 \\
\hline 5 & 1000 & 910 & 100 & 0 & 23.25 & 0 & 17353 & 21158 & 3805 \\
\hline 6 & 1100 & 1040 & 110 & 0 & 22.95 & 1120 & 20214 & 23868 & 3654 \\
\hline 7 & 1150 & 1150 & 115 & 0 & 22.50 & 1100 & 22709 & 24756 & 2047 \\
\hline 8 & 1200 & 1170 & 120 & 0 & 22.15 & 0 & 23106 & 27344 & 4238 \\
\hline 9 & 1300 & 1300 & 130 & 0 & 22.80 & 1800 & 26184 & 29640 & 3456 \\
\hline 10 & 1400 & 1400 & 140 & 120 & 29.35 & 340 & 29048 & 41442 & 12394 \\
\hline 11 & 1450 & 1412 & 145 & 0 & 30.15 & 0 & 29048 & 42572 & 13524 \\
\hline 12 & 1500 & 1412 & 150 & 0 & 31.65 & 0 & 29048 & 44690 & 15642 \\
\hline 13 & 1400 & 1400 & 140 & 120 & 24.60 & 0 & 29048 & 36953 & 7905 \\
\hline 14 & 1300 & 1300 & 130 & 0 & 24.50 & 0 & 26184 & 31850 & 5666 \\
\hline 15 & 1200 & 1170 & 120 & 0 & 22.50 & 0 & 23106 & 26325 & 3219 \\
\hline 16 & 1050 & 1050 & 105 & 105 & 22.30 & 0 & 22809 & 26091 & 3282 \\
\hline 17 & 1000 & 1000 & 100 & 100 & 22.25 & 0 & 20214 & 23366 & 3152 \\
\hline 18 & 1100 & 1040 & 110 & 0 & 22.05 & 0 & 20214 & 22392 & 2178 \\
\hline 19 & 1200 & 1040 & 120 & 0 & 22.20 & 0 & 20214 & 23088 & 2874 \\
\hline 20 & 1400 & 1040 & 140 & 0 & 22.65 & 0 & 20214 & 23556 & 3342 \\
\hline 21 & 1300 & 1040 & 130 & 0 & 23.10 & 0 & 20214 & 24024 & 3810 \\
\hline 22 & 1100 & 1040 & 110 & 0 & 22.95 & 0 & 20214 & 23868 & 3654 \\
\hline 23 & 900 & 900 & 90 & 10 & 22.75 & 0 & 17353 & 20703 & 3350 \\
\hline \multirow[t]{2}{*}{24} & 800 & 800 & 80 & 80 & 22.55 & 0 & 16827 & 19844 & 3017 \\
\hline & & & & & \begin{tabular}{|l|} 
Total \\
\end{tabular} & 4360 & 519137 & 634121 & 114984 \\
\hline
\end{tabular}


and profit of the EHO based on PBUC solution for GENCO-II are higher than those of the conventional existing methods.

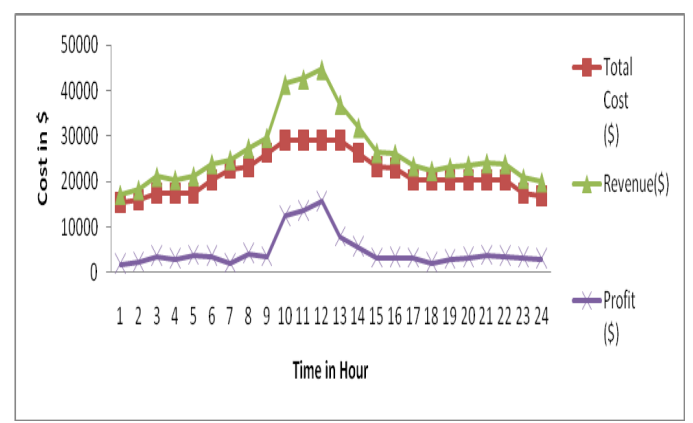

Figure 6. Comparison of Total cost, revenue and profit of 3 units' 24-hours

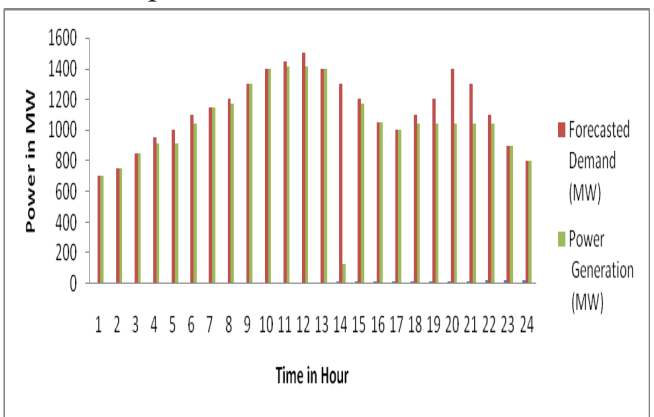

Figure 7. Comparison of demand \& generation for 24 hours

Table 7. Comparison of total cost and profit with existing search methods for PBUC

\begin{tabular}{|c|c|c|c|}
\hline S. No & Authors & Total Cost (\$) & Profit (\$) \\
\hline 1 & Tim \& Sheble & 623441 & 27889 \\
\hline 2 & Kazarlis et.al & 610500 & 40830 \\
\hline 3 & Swarup et. al & 609023 & 42306 \\
\hline 4 & Ganguly et. al & 591715 & 59615 \\
\hline 5 & Logavani et.al & 581541 & 69788 \\
\hline 6 & $\begin{array}{c}\text { PBUC-EHO } \\
\text { (Proposed) }\end{array}$ & 519137 & 114984 \\
\hline
\end{tabular}

\section{REFERENCES}

Annakkage, U. D., Numnonda, T. \& Pahalawaththa, N.C. (1995). Unit commitment by parallel simulated annealing, IEEE ProceedingsGeneration, Transmission \& Distribution, 142(6), 595-600.

Amudha, A. \& Christober Asir Rajan, A. (2013), Generator scheduling under competitive environment using Memory Management Algorithm, Alexandria Engineering Journal, 52, 337-346.

Asokan, K. \& Ashokkumar, R. (2014). Emission controlled profit based unit commitment for Gencos using MPPD table with ABC algorithm under competitive environment, WSEAS Transactions on Systems, 13, 523-543.

\section{Conclusion}

In this article a new meta-heuristic approach, the Elephant Herding optimization algorithm is utilized to get solution for the PBUC problem under deregulated power marketplace. This works on grouping behavior of the elephants in the clan. Based on the exploration and exploitation operator of the Elephant clan, PBUC solution procedure was developed using the EHO algorithm. This makes way for extensive simulation experiment for various economic conditions. The numerical outcomes are presented with reference to the solution excellence and its features of various EHO algorithms. EHO algorithms optimally allocate the generators to evaluate the fitness value of the objective function (Profit Maximization) in a balanced and oscillated power market. The numerical results are tested on a proposed system which includes optimum UC schedule, power generation total cost, startup cost, revenue, and profit. The comparative study is also done with other benchmark existing approaches. From the solution, it is evident that the proposed elephant herding algorithm has more ability, accuracy, robustness with less computational time for the solution of power system optimization problem in a deregulated open pool market. Future enrichment of this work will concentrate on the performance improvement in a large power system with reserve uncertainty and sensitivity for reserve changes.

Attaviriyanupap, P., Kita, H., Tanka, E. \& Hasegawa, J. (2003). A hybrid LR-EP for solving new profit-based UC problem under competitive environment, IEEE Transactions of Power System, 18(1), 229-237.

Chandram, K., Subrahmanyam, N. \& Sydulu, M. (2009). Improved Pre-Prepared Power Demand Table and Muller's Method to Solve the Profit Based Unit Commitment Problem, Journal of Electrical Engineering \& Technology, 4(2), 159-167.

Chen, H. \& Wang, X. (2002), Cooperative evolutionary Algorithm for Unit Commitment, IEEE Transactions on Power Systems, 16, 128-133. 
Chendur Pandian, S. \& Duraiswamy, K. (2004).

Fuzzy Logic Implementation for Solving the Unit Commitment Problem. In International Conference on Power System Technology POWERCON, Singapore (pp. 413-418).

Columbus, C. C. \& Simon, S. P. (2011). Profit based unit commitment for GENCOs using parallel PSO in a distributed cluster, $A C E E E$ International Journal of Electrical and Power Engineering, 2(3), 24-30.

Contreras-Hernandez, E. J. \& CedenfoMaldonado J. R. (2006). A Sequential Evolutionary Programming Approach to Profit-Based Unit Commitment. In IEEE PES Transmission and Distribution Conference and Exposition Latin America, Venezuela (pp. 1-8).

Dimitroulas Dionisios, K. \& Georgilakis Pavlos, S. (2011). A new memetic algorithm approach for the price based unit commitment problem, Application of Energy, 88(12), 4687-2699.

Ganguly, D., Sarkar, V. \& Pal, J. (2004). A New Genetic Approach for Solving the Unit Commitment Problem. In Proceedings of the International Conference on Power System Technology-POWERCON2004, Singapor, 1, (pp. 542-547). DOI: 10.1109/ICPST.2004.1460054

Jing, Y., Zhou, J., Wu, W., Yang, J. \& Yu, W. (2004). Solution of the profit-based unit commitment problem by using multi-agent system. In Proceedings of the Fifth World Congress on Intelligent Control and Automation (IEEE Cat. No.04EX788), Hangzhou, China, China, 0795083. DOI: 10.1109/WCICA.2004.1343686

Kazarlis, S. A., Bakirtzis, A. G. \& Petridis, V. (1996). A Genetic Algorithm Solution to the Unit Commitment Problem, IEEE Transactions on Power Systems, 11(1), 83-92.

Logavani, K. \& Senthil Kumar, S. (2014), Solving Short Term Unit Commitment Problem Using Lambda Optimization and Modified Dynamic Programming, International Journal of Applied Engineering Research, 9(24), 27569-27579.

Mantawy, A. H., Abdel-Magid, Y. L. \& Selim, S. Z. (1998). Unit commitment by Tabu search. In Proceedings of Institutions of Electrical Engineering, Generation, Transmission and Distribution, 145(1), (pp. 56-64).

Marifield, T. T. \& Sheble, G. B. (1996). Genetic Based Unit Commitment Algorithm, IEEE Transactions on Power Systems, 11(3), 1359-1370.

Mori, H. \& Okawa, K. (2009). New MetaHeuristic Method for Profit- Based Unit Commitment Under Competitive Environment.
In IEEE Conference Power Tech, Bucharest (pp. $1-6)$.

Reddy, S. K., Panwar, L. K., Kumar, R. \& Panigrahi, B. K. (2016). Binary fireworks algorithm for profit based unit commitment problem, International Journal of Electrical Power \& Energy Systems, 83, 270-282.

Reddy, S., Panwar, L., Panigrahi, B. K. \& Kumar, R. (2019). Binary whale optimization algorithm: a new metaheuristic approach for profit based unit commitment problems in competitive electricity markets, Engineering optimization, 51(3), 369-389.

Richter, C W. \& Sheble, G. B. (1997). Genetic Algorithm Evolution of Utility Bidding Strategies for the Competitive Market Place. In 1997 IEEE/ PES Summer Meeting, Berlin, Germany, PE-752PWRS-1-05-1997, IEEE, NewYork.

Richter, C. W. \& Sheble, G. B. (2000). A Profit based Unit Commitment GA for Competitive Environment, IEEE Transactions on Power Systems, 15(2), 715-721.

Sasaki, H., Watanabe, M., Kubokawa, J. \& Yorino, N. (2002). A solution method of unit Commitment by Artificial Neural Networks, IEEE Transactions on Power Systems, 7, 974-981.

Swarup, K. S. \& Yamashiro, S. (2002). Unit Commitment Solution Methodology Using Genetic Algorithm, IEEE Transactions on Power Systems, 17(1), 87-91.

Valenzuela, J. \& Mazumdar, M. (2001). Making Unit Commitment Decisions When Electricity is Traded at Spat Market Prices. In Proceedings of IEEE Winter Meeting.

Vijay, R. \& Abhilash, M. (2018). Elephant Herding Optimization for optimum allocation of electrical distributed generation on distributed power networks, Asian Journal of electrical sciences, 7(2), 70-76.

Wang, G.-G., Deb, S. \& Coelho, L. (2015), Elephant Herding Optimization. In $20153^{\text {rd }}$ International Symposium on Computational and Business Intelligence (ISCBI 2015), Bali, Indonesia (pp. 1-5). DOI: 10.1109/ISCBI.2015.8

Yamin, H. Y., El-Dwairi, Q. \& Shahidehpour, S. M. (2007). A new approach for GENCOs profit based unit commitment in day-ahead competitive electricity markets considering reserve uncertainty, International Journal of Electrical Power Energy System, 29(8), 609-616. 